\title{
Two lessons from Christie Davies
}

\author{
Salvatore Attardo \\ European Journal of Humour Research \\ sattardo@gmail.com
}

I met Christie in 1988. He watched me deliver my first ever academic paper, in April, at the last Whimsy humour conference, which was held in West Lafayette, at Purdue University under the watchful eye of Victor Raskin, who had just recruited me for a PhD. When I saw him last, again in West Lafayette, in the summer of 2017, he reminded me of the paper I had delivered. That he recalled it is one of those amazing tricks of memory for which I admired him: he could recall details with astonishing precision, such as when he recited the chemical components that make water taste "good" (try drinking distilled water and you'll know what I am talking about). He kindly did not remind me of the sheer terror I experienced giving that paper, in front of the who's who of humour research.

Christie was a kind man, but a rigorous scholar. It is this aspect of his memory that I will talk about. The first lesson I mean is that the jokes that do not exist matter as much as those that do. Let's call this "negative evidence". I will not repeat what he wrote about it, in the (as usual) cleverly titled essay "The dog that didn't bark in the night", but the basic principle is clearly stated as follows: "what are the jokes that could easily be told in a particular society but are not?" (295). The point is that negative evidence matters just as much as positive evidence (that is, finding that some group of people use some jokes) because any interpretation that accounts for the positive and the negative evidence is more likely to be correct than one that accounts only for the positive evidence.

The point I would like to make here is that this principle matters not just in the sociological analysis of why a given society tells jokes about Poles and Italian Americans but not about, say, Swedes. Indeed, the very same principle has been successfully applied to the study of the markers of humour in conversation. In a number of articles (Pickering et al. 2009; Attardo, Pickering, \& Baker 2011; etc.) we have shown that the idea that punch lines or jab lines are uttered with "bells and whistles" (Chafe 1994: 131), or outside of the metaphor, in a marked fashion, that would highlight their presence is, simply put, false. If you look at the individual punch line, it is easy to find ways to characterize whatever intonation one finds in or around it as "marked". However, when we compared the intonation patterns of punch lines and jab lines, both in jokes and in conversation, to the baseline of the rest if the conversation (that is the nonhumorous part) we found that there were no statistical differences: the pitch, the volume, the speech rate, the pauses were not different. In fact, we found that in jokes, the pitch and volume of punch lines were lower than the rest of the text. ${ }^{1}$ 
In short, without looking at the negative evidence (what happens when we do not joke?) we could not have established that speakers do not mark humour prosodically (at least, as far as those parameters go).

The second lesson is that terminological precision matters. In his reply (Davies 2000: 469) to my review of one of his books, he credits me with characteristic generosity for insights in the applications of his ideas to linguistics. I suspect the truth is more that reading my review gave him some idea of his own. He then goes on to discuss my characterization of his theory as that the butt of jokes tend to be marginal, whereas he used the term peripheral. Of course, he was right. I had the opportunity to check with him that there is indeed a difference between the two terms and one that matters in sociology (and I guess in other disciplines as well). I did not have the heart to tell him that I had used the term carelessly in my review. Not after he had credited me with disagreeing with him. I want to be very clear: it would have been an honour to actually disagree with Christie Davies. In order to meaningfully disagree, the disagreer needs to be more or less on the same intellectual plane as the disagreed with. I did not disagree, I was just sloppy in my wording. This is not to say that we did not occasionally really disagree, most notably on the Logical Mechanisms in the GTVH, which Christie really did not like. The lesson here is: cross your t's and dot your i's: the terminology of a discipline matters, just as much as its methodology. When you borrow a concept, you should do so carefully and responsibly.

The third lesson (I never said I could count) is: when traveling wear a vest with many pockets. Christie was a kind man and an intellectual giant. He will be missed.

\section{Notes}

${ }^{1}$ This is explained by the declination of pitch and volume of the paratone (i.e., a spoken paragraph). Since punch lines tend to occur at the end of an extended monological turn (i.e., a paratone), it is not surprising to find this apparently counterintuitive result.

\section{References}

Davies, C. (1998). 'The dog that didn't bark in the night: A new sociological approach to the cross cultural study of humor', in Ruch, W. (ed.), The Sense of Humor, Berlin and New York: Mouton de Gruyter, pp. 293-306.

Davies, C. (2000). 'Questions of power and theory: A reply to Salvatore Attardo', Humor: International Journal of Humor Research 13(4), pp. 469-72. 